WIMR

22,2

136

Received December 2005

Revised November 2006

Accepted November 2006

\section{Social relations among managers: old boys and young women's networks}

\author{
Christian Waldstrøm \\ Department of Management, CORE Research Centre, \\ Aarhus School of Business, Aarhus, Denmark, and \\ Henning Madsen \\ Aarhus School of Business, Aarhus, Denmark
}

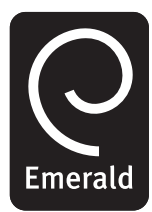

Women in Management Review Vol. 22 No. 2, 2007

pp. $136-147$

(c) Emerald Group Publishing Limited 0964-9425

DOI $10.1108 / 09649420710732097$

\begin{abstract}
Purpose - This study seeks to investigate whether there are gender differences in the importance placed on two types of network support among managers in organisations. Prior research indicates that it can be expected that female managers will not have their social contact needs satisfied to the same extent as their male colleagues and that female managers do not regard their nearest colleagues as friends to the same extent as male managers.

Design/methodology/approach - Large scale survey of managers in Denmark.

Findings - The first hypothesis is neither supported nor rejected, since the gender differences are strongly influenced by age, when controlling for sector, marital status, and children living at home. While male managers tend to see their colleagues more as friends, the older they are, the reverse is true of female managers. The second hypothesis is clearly rejected, since no gender differences are found. Originality/value - The paper identifies the crucial role of age in the gender differences in perception of social support, offering a new interpretation of female managers' use of workplace networks.
\end{abstract}

Keywords Gender, Managers, Networking, Social behaviour

Paper type Research paper

\section{Introduction}

The glass ceiling is sometimes used as a metaphor for the barrier facing women and minorities, allowing them to see the higher hierarchical positions in organisations but not reach them (Davies-Netzley, 1998). According to some authors, gender differences in the awareness and use of social networks in organisations are one of the main reasons why women earn less, get promoted less often and do not have access to as many resources as their male colleagues (Brass, 1985; Burke et al., 1995a).

Furthermore, it is often argued that female managers are more likely to make use of "soft" HRM, sometimes referred to as feminine management, which is characterised by a preference for consensus management and relationship-building, in contrast to a more controlling, formal and dominating management style (Appelbaum et al., 2003; Claes, 1999; Oakley, 2000). This importance of interpersonal competencies ought to make female managers very conscious about using their social networks within the organisation.

As a result, organisations have traditionally been characterised by a clear sex segregation in different types of jobs, leading to different career paths for men and women, with women holding positions with lower status and power within the organisation (Pfeffer, 1981). In a time when more and more women enter into the ranks of management, 
there is still no common understanding of which differences - if any - exist between male and female managers regarding their development and use of job related social networks.

Support and social interaction in the workplace plays an important part for both performance (Markiewicz et al., 2000) and in reducing stress and burnout (van Emmerik, 2002), and is, therefore, a crucial aspect to investigate. Research on gender differences show that relations with a female colleague seems to be detrimental to success but favourable to job satisfaction (Markiewicz et al., 2000).

Recent research (van Emmerik, 2006) has even shown, that while there are gender differences in the use of networks, they are neither clear-cut nor intuitive, since women were shown to be less able to create "soft social capital" than their male colleagues, as was previously assumed. However, according to Linehan (2001), access to social support is an important aspect in career success especially for female managers.

However, social networks are not necessarily a shortcut to power in an organisation, since intra-organisational social networks can have the somewhat paradoxical effect of maintaining and strengthening the formal structures (McGuire, 2000, 2002). Since, the mechanisms driving the creation and development of social networks are not explicitly defined and dictated by the formal organisation, they cannot be easily changed by formal intervention. This might be a potential barrier to those female managers who want to use social networks for personal goals within the organisation (Ridgeway, 1997).

It is the aim of this paper to test two hypotheses regarding gender differences in Danish managers' perception of on the job social support. Therefore, the following section presents the theoretical framework on gender and networks. The next section gives a short introduction to the methodological issues of the Danish survey followed by a presentation of the results. Finally, the theoretical contributions are contrasted with the results in the next section followed by a conclusion.

\section{Gender and networks}

Since, women are still a minority in managerial positions, female managers have fewer other women to choose from in their social networks (Ibarra, 1993; Moore, 1990), and since there are fewer female managers at the very top of the hierarchy, they do not have the same leverage within the organisation (Brass, 1985, 1992; McGuire, 2000). Moreover, female managers often feel that they have to change their managerial style in order to reach the highest management levels, specifically in their conscious effort to gain access to the social networks known as old boys networks (Davies-Netzley, 1998). This was confirmed by Rutherford (2001), who found that gender differences in management style tended to decrease at the top of the hierarchy.

While some differences seem to be innate to each gender, research has successfully identified a number of ways in which gender roles are self-fulfilling and socially constructed (Ely, 1995), particularly when compared to and by men (Wilson, 2005). One important way that this manifests itself in the social structure is in the homophily effect (Rogers and Kincaid, 1981), which is the preference for creating relations with others, that are similar to oneself, which has shown to be exist for several characteristics, e.g. age, race, education, and sex (Brass, 1985).

For women as minority in many managerial jobs, this has led to a discussion of whether the same-sex relations are indeed a consequence of choice or induced homophily (McPherson and Smith-Lovin, 1987; Mehra et al., 1998) - i.e. whether women actively choose to interact with other women, or whether they are forced to this network preference by exclusion of male networks or because of lack of organisational power. 
WIMR

22,2

138
Therefore, two distinct approaches to explaining gender differences in organisations have been identified: a human capital approach and a systemic barriers approach (Ibarra, 1992, 1997). In the human capital approach, differences in organisational achievement and position in the social network are due to personal achievement and formal position rather than organisational characteristics. Conversely, the systemic barriers approach highlights the inherent expectations, preferences and biases of the organisational members as the main source of gender differences across social networks. While such approaches have given researchers a tool for analysing gender differences, empirically, no conclusive explanatory power as regards differences in women's and men's networks has been given (Brass, 1985; Burt, 1999; Moore, 1990; Pugliesi and Shook, 1998).

Ibarra $(1992,1997)$ found that men and women seek and use social networks in different ways: while men tend to have ties and relations with other men in their networks, women seem to develop dual networks - one consisting primarily of relationships with other women, to satisfy the need for friendships and support (expressive network relationships), and another consisting of dominant men in the organisation, to satisfy the need for advice and organisational knowledge (instrumental network relations). The preference and use of gender-segregated, expressive networks has been linked to power and promotion within organisations (Brass, 1985; Moore, 1990), often termed the "old boys network".

Typically, the most powerful individual in the organisation will also be the most attractive to others, giving them the possibility to form more links, further enhancing their power and status in the network. This leads to another aspect of gender differences in social networks: since homophily in network development is rather strong (Burke et al., 1995a, b; Ibarra, 1992, 1997; McPherson et al., 2001), the imbalances and structural differences inherent in the organisation will tend to be maintained or even reinforced (McGuire, 2002). As expressed by Ibarra (1992, p. 425), "[. . . preferences for homophily and status will tend to coincide for men and exist in competition for women".

However, the reverse is likely to be true in cases where men are in the minority (Burt, 2000), as proposed by Ibarra (1993, p. 81) “... the extent to which certain of the network patterns [...] are also found in contexts where members of a majority group, from a societal standpoint, are in the minority within their organisational context". This is of interest for this study since male managers may actually be in a minority in some industries and especially in parts of the public sector.

Since, most managerial positions are filled by men, it is likely that female managers are less likely to develop friendship relations with their nearest (mostly male) colleagues. This leads to the first hypothesis:

H1. Female managers do not regard their nearest colleagues as friends to the same extent as male managers.

Several findings highlight "good personal relationships" and "communication skills" as particularly important for female managers (Priola, 2004; Rosener, 1990). However, research shows that traditionally, female managers have not used informal communication and non-formal management techniques consciously as part of their managerial work to the same extent as their male colleagues (Pfeffer, 1981; Reif et al., 1975), e.g. in gaining promotions (Cannings and Montmarquette, 1991). This has been contested, however, since women seem to use social networks just as much as men, or even more (Brass, 1985; McGuire, 2000; Stewart and Gudykunst, 1982). Research has even shown that 
female managers tend to attach more importance to the necessity of developing and using social networks (Davies-Netzley, 1998; McGuire, 2002).

This preference for the relational aspects of managing is not likely to be as easily satisfied for female managers, however, given the skewed gender distribution in the managerial ranks and homophilious preferences. Thus, presented as the second hypothesis:

H2. Female managers will not have their needs for social contact satisfied through their job to the same extent as their male colleagues.

139

In order to control for factors likely to influence these two hypotheses, a number of control variables are presented in the following.

Traditionally there has been a perceived difference between the public and the private sector. The differences in gender distribution in the two sectors, particularly in management levels make it very critical to distinguish between those two types of organisations and to control for inter-sector effects. So far, there has not been a lot of research into network structures in public organisations with (Moore, 1992) as a notable exception.

Only a small number of research papers deal explicitly with gender differences in intra-organisational managerial networks so it is important to bear in mind the differences between managers' and non-managers' networks, as presented in (Carroll and Teo, 1996). They found that managers have more diverse and stronger networks than non-managers, and the question, therefore, is whether a difference similar to the one between non-managers and managers can be found between managers at the bottom and top of organisations, specifically whether managers at the top of the organisation to a higher or a lesser extent receive social support from their social networks with colleagues. This could indicate potential differences in the perception of the social environment between managers at the various levels.

Studies on burn-out and stress have highlighted the effect of both practical and socio-emotional support from spouse without any clear cut results: in an academic setting, van Emmerik (2002) found no effects of spousal support, while other studies have presented contradicting results in other settings (Frone and Yardley, 1996; Lee and Duxbury, 1998). Linehan (2001) presented evidence that the traditional homemaker role has strong influence on women managers ability to network as much with their colleagues compared to male managers.

Finally, the age of the manager can be thought to have an effect on the social relations of managers in the workplace, and a study of accounting professionals (Moyes et al., 2006) showed some clear age and gender interactions affecting job satisfaction.

Therefore, data on private/public affiliation, the managers' position in the managerial hierarchy, age of the manager and marital status and whether the manager has kids at home should be controlled for.

\section{Method}

Data of relevance for testing the two hypotheses stated above are extracted from a large-scale questionnaire-based survey of Danish managers in private as well as public organisations. The respondents are sampled randomly from various databases on Danish organisations and the sample size is 1,500 respondents and the response rate is approximately 65 per cent.

The question of relevance for the hypotheses in this paper deals with how managers perceive their working conditions and environment. The overall question is elaborated 
WIMR

22,2

140 into a scale with 25 items each of which describe different aspects of the managerial job. The responses are given on a five-point ordinal scale ranging from no importance at all to very high importance.

The character of the information points to an initial analysis which can identify potential underlying structures in the overall question concerning managers' perception of their working conditions and by this evaluate if working conditions related to social interaction is perceived differently from other working conditions. If such underlying structures exist the detailed analyses may be simplified. Therefore, the information is initially analysed by a factor analysis based on a principal component extraction followed by a varimax rotation.

Some background information like age and gender of the respondent, their managerial position, their marital status, and if they have children living at home is available from the survey as well. By using this information, it is possible to carry out analyses which may suggest if the perception of working conditions related to social interaction is influenced by such socio-demographic characteristics. A logistic regression is applied to pursue this purpose using a backward elimination procedure with a critic level of significance set at 5 per cent and respecting the hierarchical principle.

The background information included in the analyses are: gender (male, female), age (40 or less, $41-50$, more than 50), managerial level (top, middle, lower), sector (private, public), marital status (living alone, married or living with a partner), and children living at home (no, yes). Furthermore, interactions between gender and the remaining five explanatory factors have been included as well to take account of potential interrelationships.

The results of the analyses will be presented in the next section.

\section{Results}

The survey information shows that 25 per cent of managerial positions in Danish organisations are taken up by women. However, there are more female managers in the public sector than in the private sector ( 41 and 14 per cent, respectively). Furthermore, 23 per cent of the managers see themselves as lower managers, 49 per cent as middle managers, and 28 per cent as top managers. Female managers are in majority at the lower level in the public sector and almost equivalent to the number of male managers at the middle level. But at the top level, they constitute a minority.

Only 20 per cent of the managers are 40 years of age or less. The remaining managers fall almost equally into the age groups 41-50 years or above 50 years. Male managers follow this general distribution whereas the majority of female managers are in the age group $41-50$ years. Only 10 per cent of the managers are living on their own. But it is more normal among female managers (20 per cent) compared to male managers ( 6 per cent). The majority of managers have children living at home (54 per cent). Male managers are just a little above this level (55 per cent) whereas only 48 per cent of female managers have children living at home.

These initial analyses points to variations in the composition of managers in Danish organisations. Such differences suggest that the managerial job could be perceived differently among the various groups of managers. But before the background information is included in more detailed analyses a factor analysis is carried out to obtain an impression of the underlying structure in the responses to the question concerning managers' perception of their working conditions. The result is presented in Table I.

As can be seen from Table I, the factor analysis resulted in six factors. The six factors account for almost 60 per cent of the variation in the responses to the 25 items in Table I, and 


\begin{tabular}{lrl}
\hline Factor & Item & Item text \\
\hline 1. Life/work-balance & 19 & I cannot separate work and free time \\
& 17 & In principle I am available for my job 24 hours a day \\
& 9 & I think about my job when I am off work \\
& 18 & It is difficult for me to earmark time for holidays \\
& 6 & It is difficult to satisfy my ambitions in relation to family \\
& 11 & and free time on one hand and my work on the other hand \\
2. Work control & 10 & I have influence on prioritising my tasks \\
& 7 & I have influence on the content of my job \\
& 12 & I experience freedom for decisions in my job \\
& 8 & My work includes traveling \\
& 21 & I can back out if the pressure becomes too great \\
& 25 & My job is exciting and challenging \\
& 24 & I have options for development in my job \\
3. Work autonomy & 4 & I have a clearly defined authority \\
& 3 & I have a clearly defined responsibility \\
4. Work overload & 5 & I have authority which matches my responsibility \\
& 1 & The number of tasks is too big \\
5. Work friendship & 2 & I deal with many different problems during a working day \\
& 23 & My nearest colleagues are also my friends \\
& 22 & My and my fellow managers are supporting each other \\
6. Work role & 16 & I do not feel alone in my job \\
& 14 & It is a lifestyle to be a manager \\
& 15 & I must balance different interests daily \\
& 13 & The job satisfies my need for social contacts
\end{tabular}

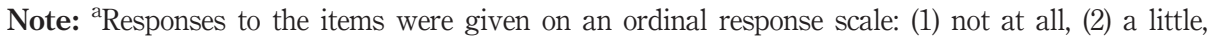
(3) to some extent, (4) to a high extent, (5) to a very high extent

\section{Social relations} among managers

141

Table I. Managers perception of their working conditions grouped according to the latent factor structure ${ }^{\mathrm{a}}$

only a few secondary loadings demonstrate possible alternative relationships. The items loading on the first four factors can be characterised as different practical aspects of the job as indicated by the labelling of these factors. As such they are of no interest for the hypotheses in question. However, the two remaining factors in Table I are directly related to the hypotheses stated: factor 5 characterised as "work friendship" and factor 6 characterised as "work role". In factor 5, item 23 seems to be the most obvious representative to pick-up for a more detailed analysis and likewise for item 13 in factor 6 . Since, the two items load on different factors, it seems appropriate and legitimate to discuss a more detailed analysis based on the logistic regression approach as two separate analyses.

However, before the logistic regression model can be applied the responses to how the job satisfies the need for social contacts and the extent to which nearest colleagues are seen as friends have to be transformed into binary variables (the full response scale is included in Table I). Since, the frequency distributions are not alike it seems most appropriate to group the two selected items the following way:

(1) concerning the perception of how the job satisfies the need for social contacts the first three response options (not at all, a little, and to some extent) is taken as a no whereas the remaining two response options (to a high extent and to a very high extent) is taken as yes; and 
WIMR

22,2

142

(2) concerning if they see their nearest colleagues as friends or not the first two response options (not at all and a little) is taken as a no whereas the remaining three response options (to some extent, to a high extent, and to a very high extent) is taken as a yes.

Nearest colleagues are seen as friends

The result of the backward elimination procedure makes it possible to suggest that sector, marital status, and children living at home do not significantly influence the perception of how the managers see their nearest colleagues as friends. This leaves back three explanatory factors with a significant influence: gender, age, and managerial level. Furthermore, the interaction between gender and age is significant. The result is presented in Tables II and III.

The results in Tables II and III show that managers at the top level are more likely to regard their nearest colleagues as friends compared to middle as well as lower managers. But the result also shows middle managers to be more likely to regard their nearest colleagues as friends compared to lower managers.

The significant interaction between gender and age indicates a mixed pattern in the perception of nearest colleagues seen as friends. Compared to female managers above 50 years of age it seems more probable that managers in all other combinations of gender and age see their nearest colleagues as friends. It is most visible for male managers above 50 years of age. For managers of age 50 or below there is a remarkable shift. The probability that male managers of age 41-50 see their nearest colleagues as friends is slightly higher compared to female managers in the same age group. But in the age group 40 or below the situation is reversed and the difference is more notable. Thus, is seems as if male managers more and more see their nearest colleagues as friends the older they are, the reverse is true for female managers.

\section{Satisfaction of need for social contacts}

The backward elimination procedure shows that gender, managerial level, marital status, and children living at home does not seem to have a significant

\begin{tabular}{|c|c|c|}
\hline & \multicolumn{2}{|c|}{ Gender } \\
\hline Age & Male & Female \\
\hline 40 or less & 0.367 & 0.562 \\
\hline $41-50$ & 0.559 & 0.550 \\
\hline Above 50 & 0.995 & 0 \\
\hline
\end{tabular}

Table II.

Note: Significant explanatory factors influencing if nearest colleagues are seen as friends (identified by the logistic regression analysis): gender age interaction

\begin{tabular}{lcc} 
Top & Middle & Lower \\
\hline 0.644 & 0.161 & 0
\end{tabular}

Table III.

Note: Significant explanatory factors influencing if nearest colleagues are seen as friends (identified by the logistic regression analysis): managerial level 
influence on the perception of how the need for social contacts is satisfied by the managerial job.

Since, gender is excluded so are all the potential interactions according to the hierarchical principle. That is, the only factors which influence the perception of how the need for social contacts is satisfied by the managerial job are sector and managerial level, which is presented in Tables IV and V.

The results in Tables IV and V show that managers in the public sector to a higher degree have their need for social contact satisfied by their job compared to managers in the private sector. Concerning the managerial level it is less probable that managers of age 50 years or below have their need for social contact satisfied by their job compared to managers compared to managers above 50 years.

\section{Discussion}

First of all, it is interesting to note that the initial factor analysis did not identify the two focal items (13 and 23) as part of the same factor. This indicates that managers perceive social aspects of their jobs in a more complex way than just receiving more or less support. Therefore, it is necessary to understand the two dimensions of personal network support in organisations, here termed work friendship and work role.

$H 1$ that female managers do not regard their nearest colleagues as friends to the same extent as male managers, is supported. However, while there are some important differences between male and female managers, they are strongly influenced by age, when controlling for sector, marital status, and children living at home.

While male managers tend to see their colleagues more as friends the older they are, the reverse is true of female managers. Thus, the older female managers, who are likely to have felt the "token effect" (Kanter, 1977) seem to follow the theoretical findings, that there is a clear difference between male and female mangers when it comes to regarding nearest colleagues as friends. However, younger female managers are far more likely to have friends among their nearest colleagues.

The implications of this finding are not clear, but it is noteworthy that age and gender have a significant interaction effect and not gender and hierarchical level. While hierarchical level and age are correlated to some degree, the implication is that there is a stronger generational effect than hierarchical when it comes to gender differences. This hints at the both an "Old Boys Networks" and "Young Women's Networks".

Public Private

0.354

0

Note: Significant explanatory factors influencing if the need for social contacts is satisfied by the managerial job (identified by the logistic regression analysis)

\begin{tabular}{ccc}
\hline 40 or less & $41-50$ & More than 50 \\
\hline-0.42 & -0.323 & 0
\end{tabular}

Note: Significant explanatory factors influencing if the need for social contacts is satisfied by the managerial job (identified by the logistic regression analysis)
Social relations among managers

143 
WIMR

22,2

\section{4}

This research cannot determine whether the shift in manager's perception of their nearest colleagues as friends change as they get older or whether this is part of a change in perception of workplace relations due to changes in generations. Since, older female managers are more likely to have felt the token effect (Oakley, 2000), this could explain why they to a lesser extend see their nearest colleagues (who are more likely to be men) as friends. With more women entering the managerial ranks nowadays, it is more likely that this is a generational issue.

$H 2$ that female managers will not have their needs for social contact satisfied through their job to the same extent as their male colleagues, is clearly rejected, since no gender differences are found.

Since, there is no difference between genders in the extent to which the workplace satisfies their social contacts, and given the well described homophilious preferences, it is, therefore, likely that female managers have friendship relations with more distant colleagues. It can, therefore, be assumed that female managers' homophilious preference for networks with other female managers could lead to more interdepartmental relations if there are few other women in the same department. Studies show that interdepartmental ties which span structural holes could lead to individual and organisational advantages (Burt, 1999, 2000; Granovetter, 1983; Podolny and Baron, 1997).

\section{Limitations}

One factor which might have influenced the results of this paper is that much of the organisational social network literature stems from Anglo-American research, while this research is based on Danish managers. Specifically, Hofstede (1997) draws attention to two significant differences between American and Scandinavian culture, namely the significantly lower power distance and the much more feminine aspects of Danish culture compared with American culture.

Since, the data used in this study stems from a Danish context, it is important to bear in mind Scandinavian management has been shown to be somewhat different from management elsewhere (Smith et al., 2003). While the effects of this may not be evident, some indications might be identified. A feminine culture is characterised by, among other things, a preference egalitarianism, both in society and in organisations (Hofstede, 1997). Therefore, gender differences in the use of social networks in the various hierarchical levels are likely to be less important in Danish companies than in many other countries. Similarly, the bias of the feminine value system towards non-tangible values might lead to smaller gender differences in management styles and preferences. The difference between male and female managers might thus be expected to be less evident in the much more feminine Scandinavian countries, and the differences identified in this paper are likely to be more explicit in most other cultures. However, cross-cultural research indicates that there is a significant homogeneous pattern in gender differences in social networks across national cultures (Moore, 1988). Thus, bearing the above-mentioned issues in mind, the results of this paper could well be generalised to other countries.

\section{Conclusion}

This paper demonstrates that some aspects of the research hypotheses could be confirmed whereas others could be rejected. That is, the situation concerning managers and their social network seems to be more complex than has previously been presented in the literature on gender and social relations in the workplace. 
There may be more reasons for this situation. One of them is that what has been reported previously in the literature is normally dealing with social networks in general. But social networks of managers may differ from this general situation. And it certainly turns out that there seems to be a major difference between the private and the public sector.

Thus, there is a strong basis for concluding that while there are general gender differences, they are embedded in more important differences due to structural properties of the labour market, affiliation with a given managerial level and differences between the among managers public and private sector. It is, therefore, more likely that the most interesting effect is same-gender and different-gender relationships and the overall gender distribution in the workplace - not the gender of the individual.

From a research point of view, one implication is that our knowledge of social networks in different organisational sectors needs to be investigated further. It is also of interest to investigate the observed differences in the Danish context in more depth in order to achieve more explanations of the observed results. Finally, the findings observed among Danish managers could be further clarified by cross-country comparisons.

From a business point of view, there is a need to challenge some of the commonly held views of gender differences in friendship networks and social support in an organisational setting. By understanding the interrelated roles of age and gender in managerial networks, it is possible to understand homophilious social support as a more complex concept and use this insight to better understand the challenges of both male and female managers in difference stages in life.

Future research would need to more explicitly identify the role of same-gender relations in the managerial networks of expressive relationships. This would make it possible to further explain and qualify the importance of age in the gender difference in managerial network.

\section{References}

Appelbaum, S.H., Audet, L. and Miller, J.C. (2003), "Gender and leadership? Leadership and gender? A journey through the landscape of theories", Leadership \& Organization Development Journal, Vol. 24 No. 1, pp. 43-51.

Brass, D.J. (1985), "Men's and women's networks: a study of interaction patterns and influence in an organization”, Academy of Management Journal, Vol. 28 No. 2, pp. 327-43.

Brass, D.J. (1992), "Power in organizations: a social network perspective", Research in Politics and Society, Vol. 4, pp. 295-323.

Burke, R.J., Bristor, J.M. and Rothstein, M.G. (1995a), "The role of interpersonal networks in women's and men's career development", The International Journal of Career Management, Vol. 7 No. 3, pp. 25-32.

Burke, R.J., Rothstein, M.G. and Bristor, J.M. (1995b), "Interpersonal networks of managerial and professional women and men: descriptive characteristics", Women in Management Review, Vol. 10 No. 1, pp. 21-7.

Burt, R.S. (1999), “The gender of social capital”, University of Chicago Selected Paper, No. 80, p. 40.

Burt, R.S. (2000), “The network structure of social capital”, in Staw, B.M. and Sutton, R.I. (Eds), Research in Organizational Behavior,Vol. 22, Elsevier, New York, NY, pp. 345-423.

Cannings, K. and Montmarquette, C. (1991), "Managerial momentum - a simultaneous model of the career progress of male and female managers", Industrial \& Labor Relations Review, Vol. 44 No. 2, pp. 212-28. 
WIMR

22,2

146

Carroll, G.R. and Teo, A.C. (1996), "On the social networks of managers", Academy of Management Journal, Vol. 39 No. 2, pp. 421-40.

Claes, M-T. (1999), "Women, men and management styles”, International Labour Review, Vol. 138 No. 4, pp. 431-46.

Davies-Netzley, S.A. (1998), "Women above the glass ceiling: perceptions on corporate mobility and strategies for success", Gender \& Society, Vol. 12 No. 3, pp. 339-55.

Ely, R.J. (1995), “The power in demography: women's social constructions of gender identity at work", Academy of Management Journal, Vol. 38 No. 3, pp. 589-634.

Frone, M.R. and Yardley, J.K. (1996), "Workplace family-supportive programmes: predictors of employed parents' importance ratings”, Journal of Occupational \& Organizational Psychology, Vol. 69 No. 4, pp. 351-67.

Granovetter, M. (1983), "The strength of weak ties: a network theory revisited", Sociological Theory, Vol. 1, pp. 201-33.

Hofstede, G.H. (1997), Cultures and Organizations: Software of the Mind, McGraw-Hill, London.

Ibarra, H. (1992), "Homophily and differential returns: sex differences in network structure and access in an advertising firm”, Administrative Science Quarterly, Vol. 37 No. 3, pp. 422-47.

Ibarra, H. (1993), "Personal networks of women and minorities in management: a conceptual framework", Academy of Management Review, Vol. 18 No. 1, pp. 56-87.

Ibarra, H. (1997), "Paving an alternative route: gender differences in managerial networks", Social Psychology Quarterly, Vol. 60 No. 1, pp. 91-102.

Kanter, R.M. (1977), "Some effects of proportions on group life: skewed sex ratios and responses to token women", The American Journal of Sociology, Vol. 82 No. 5, pp. 965-90.

Lee, C.M. and Duxbury, L. (1998), "Employed parents' support from partners, employers, and friends", Journal of Social Psychology, Vol. 138 No. 3, pp. 303-23.

Linehan, M. (2001), "Networking for female managers' career development - empirical evidence", Journal of Management Development, Vol. 20 No. 10, pp. 823-9.

McGuire, G.M. (2000), “Gender, race, ethnicity, and networks", Work and Occupations, Vol. 27 No. 4 , pp. $500-23$.

McGuire, G.M. (2002), "Gender, race, and the shadow structure - a study of informal networks and inequality in a work organization”, Gender \& Society, Vol. 16 No. 3, pp. 303-22.

McPherson, M.J. and Smith-Lovin, L. (1987), "Homophily in voluntary organizations: status distance and the composition of face-to-face groups", American Sociological Review, Vol. 52 No. 3, pp. 370-9.

McPherson, M., Smith-Lovin, L. and Cook, J.M. (2001), "Birds of a feather: homophily in social networks", Annual Review of Sociology, Vol. 27, pp. 415-44.

Markiewicz, D., Devine, I. and Kausilas, D. (2000), "Friendships of women and men at work", Journal of Managerial Psychology, Vol. 15 No. 2, pp. 161-84.

Mehra, A., Kilduff, M. and Brass, D.J. (1998), "At the margins - a distinctiveness approach to the social identity and social networks of underrepresented groups", Academy of Management Journal, Vol. 41 No. 4, pp. 441-53.

Moore, G. (1988), "Women in elite positions: insiders or outsiders?", Sociological Forum, Vol. 3 No. 4, pp. 566-85.

Moore, G. (1990), “Structural determinants of men's and women's personal networks”, American Sociological Review, Vol. 55 No. 5, pp. 726-35.

Moore, G. (1992), "Gender and informal networks in state government”, Social Science Quarterly, Vol. 73 No. 1, pp. 46-61. 
Moyes, G.D., Williams, P.A. and Koch, B. (2006), "The effects of age and gender upon the perceptions of accounting professionals concerning their job satisfaction and work-related attributes", Managerial Auditing Journal, Vol. 21 No. 5, pp. 536-61.

Oakley, J.G. (2000), "Gender-based barriers to senior management positions: understanding the scarcity of female CEOs", Journal of Business Ethics, Vol. 27 No. 4, pp. 321-34.

Pfeffer, J. (1981), Power in Organizations, Pitman Publishing, Marchfield.

Podolny, J.M. and Baron, J.N. (1997), "Resources and relationships: social networks and mobility in the workplace", American Sociological Review, Vol. 62 No. 5, pp. 673-93.

Priola, V. (2004), "Gender and feminine identities - women as managers in a UK academic institution", Women in Management Review, Vol. 19 No. 8, pp. 421-30.

Pugliesi, K. and Shook, S.L. (1998), "Gender, ethnicity, and network characteristics: variation in social support resources”, Sex Roles, Vol. 38 No. 3, pp. 215-38.

Reif, W.E., Newstrom, J.W. and Monczka, R.M. (1975), "Exploding some myths about women managers", California Management Review, Vol. 17 No. 4, pp. 72-9.

Ridgeway, C.L. (1997), "Interaction and the conservation of gender inequality: considering employment”, American Sociological Review, Vol. 62, pp. 218-35.

Rogers, E. and Kincaid, L. (1981), Communication Networks: Toward a New Paradigm for Research, The Free Press, New York, NY.

Rosener, J.B. (1990), “Ways women lead”, Harvard Business Review, Vol. 68 No. 6, pp. 119-26.

Rutherford, S. (2001), "Any difference? An analysis of gender and divisional management styles in a large airline", Gender - Work and Organization, Vol. 8 No. 3, pp. 326-45.

Smith, P.B., Andersen, J.A., Ekelund, B., Graversen, G. and Ropo, A. (2003), "In search of Nordic management styles", Scandinavian Journal of Management, Vol. 19 No. 4, pp. 491-507.

Stewart, L.P. and Gudykunst, W.B. (1982), "Differential factors influencing the hierarchical level and number of promotions of males and females within an organization", Academy of Management Journal, Vol. 25 No. 3, pp. 586-97.

van Emmerik, I.H. (2006), "Gender differences in the creation of different types of social capital: a multilevel study”, Social Networks, Vol. 28 No. 1, pp. 24-37.

van Emmerik, I.J.H. (2002), "Gender differences in the effects of coping assistance on the reduction of burnout in academic staff”, Work \& Stress, Vol. 16 No. 3, pp. 251-63.

Wilson, F. (2005), "Caught between difference and similarity: the case of women academics", Women in Management Review, Vol. 20 No. 4, pp. 234-48.

\begin{abstract}
About the authors
Christian Waldstrøm is an Assistant Professor at the Department of Management, Aarhus School of Business in Denmark. He has an MSc in Business and a PhD from the Aarhus School of Business. His research interests are social network analysis and social networks in an organizational context and within the framework of organisational behaviour. Christian Waldstrøm is the corresponding author and can be contacted at: cwa@asb.dk

Henning Madsen is an Associate Professor at the Department of Management, Aarhus School of Business in Denmark. He has an MSc in Mathematical Economics from the University of Aarhus and $\mathrm{PhD}$ in Business Economics from Aarhus School of Business. His current research interests include environmental management, social networks and entrepreneurship, and trends in managerial and organisational development.
\end{abstract}

To purchase reprints of this article please e-mail: reprints@emeraldinsight.com Or visit our web site for further details: www.emeraldinsight.com/reprints 